\title{
NGHIÊN CỨU MộT SỐ YẾU TỐ TIÊN LƯỢNG UNG THƯ HẮC TỐ DA TẠI BÊ̂NH VIÊ̂N K TỪ 2009 ĐẾN 2019
}

\author{
Vũ Thanh Phương ${ }^{1}$, Nguyễn Văn Chủ ${ }^{1}$, Nguyễn Đại Bình ${ }^{1}$
}

\section{TÓM TẮT}

Mục tiêu nhận xét đặc điểm lâm sàng, mô bệnh học và một số yểu tố tiên lượng ung thư hắc tố da. Đối tượng, phương pháp: mô tả tiến cứu và hồi cứu 207 bệnh nhân UTHT da giai đoạn II, III được điều trị bằng phẫu thuật tại bệnh viền $\mathrm{K}$ từ 20092019. Kết quả: bệnh hay gặp từ 40 đển 79 tuổi, tuổi trung bình $55,0 \pm 0,9$, thấp nhất 18 và cao nhất 85 , nữ/nam 1,13, vị trí hay gặp chi dưới, thể lan tràn nông $61,7 \%$, bề dây $2,1-4,0 \mathrm{~mm}$ là $29,8 \%,>4,0 \mathrm{~mm}$ là $67,4 \%$. Clark V $51,8 \%$, Clark IV $34 \%$, giai đoạn thẳng đứng $75,2 \%$, nhân vê tinh $30,5 \%$, loét u $43,2 \%$, xâm nhập mạch $22 \%$. U xâm lấn trung bì có số nhân chia $>6 / \mathrm{mm}^{2} 38,3 \%$, lympho xâm nhập u thưa thớt $33,3 \%$ và không có lympho bào $36,2 \%$. Chưa di căn hạch khu vực 45,9\%, giai đoạn 2, 3 là $45,9 \%$ và $54,1 \%$, sống thêm 5 năm toàn bộ $42,4 \%$. Các yếu tố ảnh hưởng đến sống thêm 5 năm vị trí u, típ mô bệnh học, độ dầy u, Clark, giai đoạn phát triển, vệ tinh, loét u, xâm nhập mạch, tỳ lệ nhẩn chia, lympho xâm nhập u, số hach khu vực di căn và giai đoạn bệnh. Kệt Iuận: Bệnh hay gặp từ 40 đến 79 tuổi, nữ/nam 1,13, vị trí hay gặp chi dưới, thể lan tràn nông $61,7 \%$, bế dây $>4,0 \mathrm{~mm} 67,4 \%$, Clark V 51,8\%, gđ thẳng đứng $75,2 \%$, nhân vệ tinh $30,5 \%$, loét u 43,2\%, xâm nhập mạch $22 \%$, u xâm lấn trung bì có số nhân chia > $6 / \mathrm{mm}^{2} 38,3 \%$, di căn hạch khu vực là $54,1 \%$, giai đoạn 2,3 là $45,9 \%$ và $54,1 \%$. Sống thêm 5 năm toàn bộ $42,4 \%$, yếu tố tiên lượng là vị trí $u$, típ $M B H$, độ dẩy u, Clark, giai đoạn phát triển, vệ tinh, loét u, xâm nhập mạch, tỳ lệ nhân chia, lympho xâm nhập u, số hạch di căn và giai đoạn bệnh.

Tư khóa: ung thư hắc tố da, yếu tố tiện lượng, mô bệnh học

\section{SUMMARY \\ STUDY SOMES PROGNOSTICS FACTORS OF CUTANEOUS MELANOMA AT K HOSPITAL FROM 2009 TO 2019 \\ Objective: Study on clinical,histopathological} featuresand some prognostic factors of cutaneous melanoma. Subjects and methods: A retrospective and prospective study on 207 cutaneous melanoma patients in stage II, III were treated with surgery at K hospital from 2009 to 2019. Results: The average age is $55,0 \pm 0,9$, which is common from 40 to 79 years, youngest patient 18 years-old and the oldest one 85 years-old, female/male 1,13. Tumors are often located in the lower limbs, superficial spreading

\section{*Bênh viên $K$}

Chịu trách nhiệm chính: Vũ Thanh Phương

Email vuthanhphuonghm@gmail.com

Ngày nhận bài: 28/8.2021

Ngày phản biên khoa họ: 15/9/2021

Ngày duyệt bài: 1/10/2021

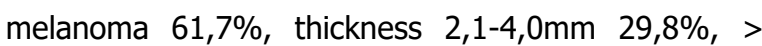
$4,0 \mathrm{~mm} 67,4 \%$. Clark V 51,8\%, Clark IV 34\%, the vertical development stage $75,2 \%$, satellite $30,5 \%$, ulcer $43,2 \%$, invasion to blood vessel $22 \%$. In tumors invade mesoderm, mitosis $>6 / \mathrm{mm}^{2} 38,3 \%$, sparse invasive lymphocytesgroup 33,3\%, without invasive lymphocytes group 36,2 \%. Lymph node metastasis $45,9 \%$, stage 2,3 is $45,9 \%, 54,1 \%$. The overall $5-$ year survival rate is $42.4 \%$. Prognostic factors affect the overall 5-year survival rate: tumor location, histopathological type, thickness, Clark, developmental stage, satellite, ulcer, invasion to blood vessel, invade mesoderm, invasive lymphocytes, number of lymph nodes metastasis and stage. Conclusion: Common age $40-70$, female/male is 1,13 , lower limbs $62,3 \%$, superficial spreading melanoma $61,7 \%,>4,0 \mathrm{~mm}$ $67,4 \%$. Clark V 51,8\%, the vertical development stage $75,2 \%$, satellite $30,5 \%$, ulceration $43,2 \%$, invasion to blood vessel $22 \%$, invade mesoderm, mitosis > $6 / \mathrm{mm} 2$ is $38,3 \%$. Lymph node metastasis $45,9 \%$, stage 2,3 is $45,9 \%, 54,1 \%$. The overall 5 -year survival rate $42.4 \%$. Prognostic factors: tumor location, histopathological type, thickness, Clark, developmental stage, satellite, ulcer, invasion to blood vessel, invade mesoderm, invasive lymphocytes, number of lymph nodes metastasis and stage.

Key: Cutaneous melanoma, prognostic factors, histopathology

\section{I. ĐẶT VẤN ĐỀ}

Ung thư hắc tố (UTHT) da là bệnh lý ác tính của các tế bào sinh sắc tố melanin ở da. Các tế bào này phân bố chủ yếu ở lớp đáy của thượng bì (90\%), niêm mạc, màng não, võng mạc mắt, sinh dục, đại trực tràng, ống hậu môn, UTHT da là bệnh rất ác tính, tiến triến nhanh, di căn sớm [1]. Tỷ lệ mắc tăng liên tục ở hâuu hết các nước trong nhiêuu thập kỷ qua, bệnh đang ngày càng có xu hướng phổ biến ở các nước châu Âu, châu Mỹ, Úc và Newzealand. Tại Mỹ, theo hiệp hội ung thư Hoa Kỳ, 2020 có 100.350 ca mắc mới trong đó 60.190 nam, 40.160 nữ và 6.850 ca tử vong do bệnh này, trong đó 4.610 nam và 2.240 nữ. Là bênh phổ biến thứ 5 ở nam và thứ 6 ở nư và là một trong những ung thư phát triển nhanh nhất trong các bệnh ung thư ở $M y ̃$ [2]. Ở Việt Nam, chưa có công bố cụ thể về tỷ lệ mắc và tử vong của UTHT da. Theo ghi nhận của Phạm Hoàng Anh năm 1993 tỷ lệ mắc là 0,30,4/100.000 dân, là bệnh ít gặp, nhưng đến khám và điều trị tại bệnh viện $K$ tăng lên hàng năm. Do hiểu biết về bệnh này còn hạn chế nên phân lớn bệnh nhân đển khám ở giai đoạn 2, 3 [3]. Điều trị hiện nay còn nhiều hạn chế, phẫu 
thuật là phương pháp chủ yếu khi bệnh ở giai đoạn tại chỗ, tại vùng. Nghiên cứu các yếu tố tiên lượng là tìm hiểu chúng nhằm xác định rõ vai trò để cho phẫu thuật viên lựa chọn phương pháp phẫu thuật cho từng bệnh nhân và điều trị bổ trợ thuốc miễn dịch, thuốc đích. Các yếu tố ảnh hưởng tới kết quả điều trị cũng đã được đưa ra trong các nghiên cứu ở nước ngoài, các tác giả cho rằng bề dày u là yếu tố tiên lượng quan trọng nhất. Các yếu tố khác bao gồm vị trí u, di căn hạch khu vực, xâm lấn Clark, nhân vệ tinh, loét u, u xâm lấn mạch máu, tỷ lệ nhân chia, lympho xâm nhập u cũng là các yễu tố quan trọng ảnh hưởng tới kết quả điêu trị [4]. Trong nước chưa có nghiên cứu về vấn đề này, vì vậy chúng tôi tiến hành đề tài "Nghiên cứu một số yếu tố tiên lượng ung thư hắc tố da tại bệnh viện $K^{\prime \prime}$ nhằm hai mục tiêu:

1.Nhận xét đặc điểm lâm sàng và mô bệnh học ung thư hắc tố da

2.Nghiên cứu một số yêu tố tiên lượng ảnh hưởng đến kêt quả điều trị

\section{II. ĐỐI TƯỢNG VÀ PHƯƠNG PHÁP NGHIÊN CỨU}

2.1.Đối tượng nghiên cứu: 207 bệnh nhân UTHT da giai đoạn II, III, có u nguyên phát, được phẫu thuật triệt căn đơn thuần tại viện $\mathrm{K}$ từ 2009-2019.

- Tiêu chuẩn lựa chọn: Bệnh nhân bị UTHT da giai đoạn 2,3, được phẫu thuật cắt rộng $u$, vét hạch khu vực triệt căn đơn thuần, có mô bệnh học là UTHT da, cóhồ sơ bệnh án bệnh viện lưu trữ, còn tiêu bản khối nến có đủ bệnh phẩm để chẩn đoán mô bệnh học và hóa mô miễn dịch.

- Tiêu chuẩn loại trừ: Các trường hợp không đủ tiêu chuẩn trền.

2.2. Phương pháp nghiên cứu: Mô tả, kết hợp tiến cứu và hồi cứu.

- Cỡ mẫu, chọn mẫu: theo phương pháp lấy mẫu toàn bộ, chọn mẫu có chủ đích, cỡ mẫu của chúng tôi là 207 trường hợp (hồi cứu 83, tiến cứu 124).

2.3. Các biến số và chỉ số: Nhóm tuổi < 20 , 20 - 39, 40 - 59, 60 - 79 và $\geq 80$ tuổi, giới nam, nữ, vị tríđầu cố, thân mình, chi trên, chi dưới, loét bề mặt $u$, nhân vệ tinh, típ mô bệnh họcthể lan tràn nông, nốt, nốt ruồi son, nốt ruồi son đỉnh. Bề dàyu $\leq 1,0 \mathrm{~mm}, 1,01-2,0 \mathrm{~mm}, 2,01-$ $4,0 \mathrm{~mm},>4,0 \mathrm{~mm}$. Clark I, II, III, IV, V, loét u vi thể, nhân vệ tinh, xâm nhập mạch máu, lympho xâm nhập u dày đặc, thưa thớt và không có lympho xâm nhập u, số nhân chia $<1 / \mathrm{mm} 2,1$ 6/mm2,> 6/mm2, hạch N0 chưa di căn, N1 di căn 1 hạch, N2 di căn 2 - 3 hạch, N3 di căn > 3 hạch, gđ 2, 3.

2.4. Quy trình nghiên cứu: Thu nhận thông tin lâm sàng qua khám bệnh nhân và hồ sơ bệnh án, làm xét nghiệm cận lâm sàng, chẩn đoán giai đoạn 2,3 vào mẫu bệnh án. Nhóm tiến cứu thì bệnh phẩm sau phẫu thuật được cố định trong formon trung tính 10\%, trong vòng 48 giờ; sau đó bệnh phẩm được pha, đúc và cắt mảnh, nhuộm theo phương pháp HE thường quy. Nhóm hồi cứu, mượn lại tất cả các tiêu bản và khối nến tại Trung tâm giải phẫu bệnh, tế bào Bẹnh viện K. Được đọc bởi các nhà giải phẫu bệnh có kinh nghiệm Bệnh viện $K$ về bề dày $u$, Clark, giai đoạn phát triển, vệ tinh, loét $u$, u xâm lấn mạch máu, tỷ lệ nhân chia, lympho xâm nhập u. Phân tích yếu tố liên quan đến sống thêm 5 năm toàn bộ, đầu vào của phân tích là nhóm bệnh nhân có tiêu chuẩn thuần nhất (UTHT da giai đoạn 2, 3 theo AJCC 2009, được cắt rộng u và vét hạch khu vực cho các trường hợp). Đầu ra của phân tích là tỷ lệ sống thêm 5 năm toàn bộ. Theo dõi bệnh nhân hẹn khám định kỳ 3 tháng 1 lần, gọi điệnđể phát hiện tái phát di căn. Thời gian sống thềm với bệnh nhân đã chết được tính theo tháng kể từ ngày mổ cho đến ngày chết do ung thư, với bệnh nhân còn sống được tính từ ngày mổ cho đến ngày kết thúc nghiên cứu.

2.5. Xử lý số liệu: Sử dụng phần mềm SPSS 20.0 để nhập, phân tích số liệu,tính tần suất, tỷ lệ phần trăm. Tính tỷ lệ sống thêm 5 nămtoàn bộ dùng phương pháp Kaplan - Meier. Phân tích đơn yếu tố dùng kiểm định Log rank tính giá trị $p$ khi phân tích từng yếu tố liên quan đến sống thêm 5 năm toàn bộ.

2.6. Đạo đức nghiên cứu: Đề cương nghiên cứu được chấp nhận bởi hội đồng khoa học viện $\mathrm{K}$. Biến số, chỉ sổ nghiên cứu thu thập một cách trung thực và khoa học.

\section{KẾT QUẢ NGHIÊN CỨU}

3.1.Đặc điểm lâm sàng, mô bệnh học

Bảng 1. Đặc điểm lâm sàng, mổ bệnh học

\begin{tabular}{|c|c|c|}
\hline Nhóm tuối & Số BN(n =207) & Tỷ lệ \% \\
\hline$<20$ & 1 & 0,5 \\
\hline $20-39$ & 23 & 11,1 \\
\hline $40-59$ & 110 & 53,1 \\
\hline $60-79$ & 63 & 30,4 \\
\hline$\geq 80$ & 10 & 4,9 \\
\hline Giới & Số BN (n =207) & \\
\hline Nam & 98 & 47,3 \\
\hline Nữ & 109 & 52,7 \\
\hline Vị trí u & Số BN (n= 207) & \\
\hline Đấu cố & 18 & 8,7 \\
\hline \multicolumn{2}{|c|}{} \\
\hline
\end{tabular}




\begin{tabular}{|c|c|c|}
\hline Thân mình & 38 & 18,3 \\
\hline Chi trên & 22 & 10,7 \\
\hline Chi dưới & 129 & 62,3 \\
\hline Mô bệnh học & Số $B N(n=141)$ & \\
\hline Thế lan tràn nông & 87 & 61,7 \\
\hline Thế nốt & 24 & 17 \\
\hline Thế nốt ruồi son & 16 & 11,3 \\
\hline Thế nốt ruồi son đỉnh & 14 & 10 \\
\hline Bề dày u $(\mathrm{mm})$ & Số $B N(n=141)$ & \\
\hline$\leq 1,0$ & 0 & 0 \\
\hline $1,1-2,0$ & 4 & 2,8 \\
\hline $2,1-4,0$ & 42 & 29,8 \\
\hline$>4,0$ & 95 & 67,4 \\
\hline Clark & Số BN $(n=141)$ & \\
\hline I & 0 & 0 \\
\hline II & 8 & 5,7 \\
\hline III & 12 & 8,5 \\
\hline IV & 48 & 34 \\
\hline V & 73 & 51,8 \\
\hline $\begin{array}{c}\text { Giai đoaan phát } \\
\text { triển }\end{array}$ & Số $B N(n=141)$ & \\
\hline Tóa tia & 35 & 24,8 \\
\hline Phát triển & 106 & 75,2 \\
\hline Vệ tinh & Số $B N(n=141)$ & \\
\hline Có & 43 & 30,5 \\
\hline Không & 98 & 69,5 \\
\hline Loét u & Số $B N(n=141)$ & \\
\hline Không & 80 & 56,7 \\
\hline Có & 61 & 43,3 \\
\hline Xâm nhập mạch & Số $B N(n=141)$ & \\
\hline Có & 31 & 22 \\
\hline Không & 110 & 78 \\
\hline Nhân chia/1mm² & Số BN(n =141) & \\
\hline$<1$ & 40 & 28,4 \\
\hline $1-6$ & 47 & 33,3 \\
\hline$>6$ & 54 & 38,3 \\
\hline Lympho xâm nhập u & Số BN(n= 141) & \\
\hline Dày đặc & 43 & 30,5 \\
\hline
\end{tabular}

\begin{tabular}{|c|c|c|}
\hline Thưa thớt & 47 & 33,3 \\
\hline Không có lympho & 51 & 36,2 \\
\hline Hạch khu vực & Số BN(n =207) & \\
\hline Chưa di căn & 95 & 45,9 \\
\hline Di căn 1 hạch & 41 & 19,8 \\
\hline 2 -3 hạch & 34 & 16,4 \\
\hline > 3 hạch & 37 & 17,8 \\
\hline Giai đoạn & Số BN(n= 207) & \\
\hline 2 & 95 & 45,9 \\
\hline 3 & 112 & 54,1 \\
\hline
\end{tabular}

Tuối trung bình là $55,0 \pm 0,9$, thấp nhất 18 và cao nhất 85 ; độ tuổi hay gặp từ 40 đến 79là $83.5 \%$, nữ/nam1.13. Vị trí gặp nhiều ở chi dưới $62,3 \%$, thể lan tràn nông $61,7 \%$, bề dây $1,1-$ $2,0 \mathrm{~mm}$ là $2,8 \%, 2,1-4,0 \mathrm{~mm}$ là $29,8 \%,>4,0 \mathrm{~mm}$ là $67,4 \%$, Clark $\vee 51,8 \%$, giai đoạn thẳng đứng $75,2 \%$, nhân vệ tinh $30,5 \%$, loét u 43,2\%, xâm nhập mạch $22 \%$. U xâm lấn trung bì có số nhân chia $>6 / \mathrm{mm} 2$ là $38,3 \%$, lympho xâm nhập u dây đặc 30,5\%, chưa di căn hạch 45,9\%, giai đoạn 2, 3 là $45,9 \%, 54,1 \%$.

3.2.Kết quả nghiên cứu các yêu tố tiên lượng

3.2.1. Sống thêm 5 năm toàn bộ sau phẫu thuật triệt căn

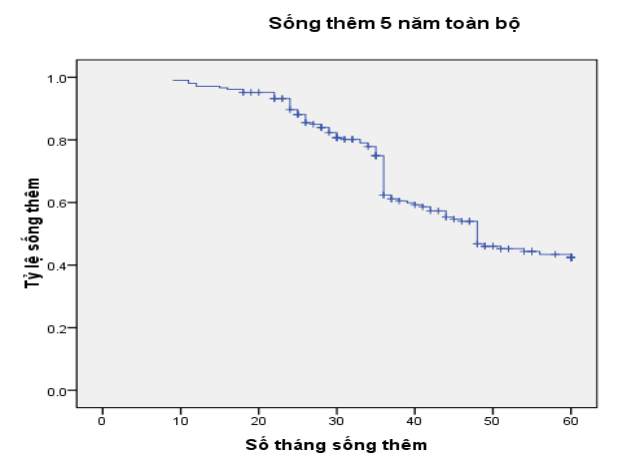

TSurvival Function
+ Censored

Biểu đồ 1. Thời gian sông thêm 5 năm toàn bộ. Sống thêm 5 năm toàn bộ là 42,4\%.

3.2.2. Yếu tố tiên lượng ảnh hưởng đến sống thêm 5 nămtoàn bộ

Bảng 2. Các yếu tốcó thể ảnh hưởng sống thêm 5 năm toàn bộ

\begin{tabular}{|c|c|c|c|c|c|c|}
\hline \multicolumn{2}{|c|}{ vốut } & \multirow{3}{*}{$\begin{array}{c}\begin{array}{c}\text { Sống thêm } \\
\mathbf{5} \text { năm\% }\end{array} \\
49,3 \\
38,7\end{array}$} & \multirow{2}{*}{$\begin{array}{c}\begin{array}{c}\text { TG sống thêm } \\
\text { TB (tháng) }\end{array} \\
47,21 \pm 1,79 \\
\end{array}$} & \multirow{2}{*}{$\begin{array}{c}\text { 95\% khoảng } \\
\text { tin cậy }\end{array}$} & \multirow{2}{*}{$\begin{array}{c}\begin{array}{c}\text { Số } \\
\text { chết }\end{array} \\
30\end{array}$} & \multirow{3}{*}{$\frac{\mathbf{p}}{0,277}$} \\
\hline \multirow{2}{*}{$\begin{array}{c}\text { Tuối } \\
(\mathrm{n}=207)\end{array}$} & $\leq 50$ tuối & & & & & \\
\hline & $>50$ tuối & & $44,77 \pm 1,40$ & $47,52-48,00$ & 67 & \\
\hline \multirow{2}{*}{$\begin{array}{c}\text { Giới } \\
(\mathrm{n}=207)\end{array}$} & Nam & 44,6 & $45,49 \pm 1,62$ & $42,30-48,67$ & 46 & \multirow{2}{*}{0,925} \\
\hline & Nũ̃ & 40.7 & $45,78 \pm 1,52$ & $42,79-48,77$ & 51 & \\
\hline \multirow{4}{*}{$\begin{array}{c}\text { Vị trí u } \\
(n=207)\end{array}$} & Đầu cố & 69,1 & $51,52 \pm 3,62$ & $44,42-58,63$ & 4 & \multirow{4}{*}{0,004} \\
\hline & Thân & 54,5 & $49,37 \pm 2,34$ & $44,68-54,06$ & 17 & \\
\hline & Chi trên & 38,3 & $47,28 \pm 2,80$ & $41,78-52,77$ & 11 & \\
\hline & Chi dưới & 35,3 & $42,71 \pm 1,48$ & $40,04-45,78$ & 65 & \\
\hline \multirow{3}{*}{$\begin{array}{l}\text { Thể mô } \\
\text { bệnh học } \\
(n=141)\end{array}$} & Lan tràn nông & 70,4 & $55,71 \pm 1,21$ & $53,34-58,08$ & 12 & \multirow{3}{*}{0,0001} \\
\hline & Thế nốt & 4,2 & $30,28 \pm 2,10$ & $26,16-34,39$ & 24 & \\
\hline & Nốt ruồi son & 62,7 & $51,90 \pm 2,84$ & $46,33-57,48$ & 6 & \\
\hline
\end{tabular}


VIETNAM MEDICAL JOURNAL N²2 - OCTOBER - 2021

\begin{tabular}{|c|c|c|c|c|c|c|}
\hline & Ruôi son đỉnh & 13,3 & $37,46 \pm 2,95$ & $31,67-43,24$ & 11 & \\
\hline \multirow{2}{*}{$\begin{array}{l}\text { Độ dày u } \\
(\mathrm{n}=141)\end{array}$} & $\mathrm{T} 2, \mathrm{~T} 3$ & 89,5 & $59,18 \pm 0,68$ & $57,83-60,53$ & 3 & \multirow{2}{*}{0,0001} \\
\hline & $\mathrm{T} 4$ & 22,3 & $41,23 \pm 1,59$ & $38,10-44,36$ & 50 & \\
\hline \multirow{2}{*}{$\begin{array}{c}\text { Clark } \\
(\mathrm{n}=141)\end{array}$} & Clark 2,3,4 & 79,8 & $57,78 \pm 0,91$ & $55,99-59,57$ & 7 & \multirow[b]{2}{*}{0,0001} \\
\hline & Clark 5 & 19,7 & $38,43 \pm 1,76$ & $34,97-41,90$ & 46 & \\
\hline \multirow{2}{*}{$\begin{array}{l}\text { Gđp.triến } \\
(\mathrm{n}=141)\end{array}$} & Tỏa tia & 92,6 & $59,13 \pm 0,59$ & $57,96-60,29$ & 2 & \multirow{2}{*}{0,0001} \\
\hline & Thằng đứng & 20,5 & $40,66 \pm 1,64$ & $37,44-43,88$ & 51 & \\
\hline \multirow{2}{*}{$\begin{array}{l}\text { Nhân vt } \\
(\mathrm{n}=141)\end{array}$} & Có vệ tinh & 5,0 & $32.28 \pm 1.53$ & $29.27-35.29$ & 37 & \multirow{2}{*}{$\begin{array}{l}0,0001 \\
0,0001\end{array}$} \\
\hline & Khồng & 77,1 & $55.34 \pm 1.14$ & $53,09-57.58$ & 16 & \\
\hline \multirow{2}{*}{$\begin{array}{l}\text { Loét u } \\
(\mathrm{n}=141)\end{array}$} & Có loét & 13,0 & $36,41 \pm 1,79$ & $32,90-39,93$ & 44 & \multirow{2}{*}{0,0001} \\
\hline & Không & 78,1 & $57,27 \pm 0,95$ & $55,39-59,14$ & 9 & \\
\hline \multirow{3}{*}{$\begin{array}{l}\text { XNmach } \\
(n=141)\end{array}$} & Có & 3,2 & $28,35 \pm 1,66$ & $25,08-31,62$ & 30 & \multirow[b]{2}{*}{0,0001} \\
\hline & Không & 63,8 & $54,05 \pm 1,11$ & $51,86-56,24$ & 23 & \\
\hline & $<1 \mathrm{~mm} 2$ & 80,7 & $55,80 \pm 1,66$ & $52,53-59,06$ & 6 & \multirow{3}{*}{0,0015} \\
\hline \multirow{2}{*}{$\begin{array}{l}\text { Nhân chia } \\
(\mathrm{n}=141)\end{array}$} & $1-6 \mathrm{~mm} 2$ & 58,5 & $53,14 \pm 2,07$ & $49,07-57,21$ & 10 & \\
\hline & $>6 \mathrm{~mm} 2$ & 12,9 & $36,91 \pm 1,93$ & $33,12-40,70$ & 37 & \\
\hline \multirow{3}{*}{$\begin{array}{c}\text { Lympho } \\
\text { xn u } \\
(n=141)\end{array}$} & Dày đặc & 80,5 & $56,73 \pm 1,52$ & $53,13-59,12$ & 6 & \multirow{3}{*}{0,0028} \\
\hline & Thưa thớt & 47,5 & $48,77 \pm 2,27$ & $44,30-53,23$ & 14 & \\
\hline & Không lympho & 20,6 & $39,21 \pm 2,22$ & $34,85-43,57$ & 33 & \\
\hline \multirow{3}{*}{$\begin{array}{c}\text { Số hạch di } \\
\text { cănn } \\
(n=111)\end{array}$} & 1 hạch & 21,7 & $42,90 \pm 2,44$ & $38,10-47,70$ & 25 & \multirow{3}{*}{0,0032} \\
\hline & 2- 3 hạch & 16,4 & $38,76 \pm 2,11$ & $34,63-42,90$ & 26 & \\
\hline & >3 hạch & 8,7 & $30,34 \pm 1,97$ & $26,47-34,20$ & 32 & \\
\hline \multirow{2}{*}{$\begin{array}{l}\text { Giaiđoạn } \\
(n=207)\end{array}$} & 2 & 77,7 & $56,08 \pm 1,04$ & $54,04-58,13$ & 14 & \multirow{2}{*}{0,0001} \\
\hline & 3 & 17,3 & $37,66 \pm 1,38$ & $34,94-40,38$ & 83 & \\
\hline
\end{tabular}

Yếu tố nhóm tuổi, giới sống thêm 5 năm toàn bộ là khác nhau, nhưng không có ý nghĩa với $\mathrm{p}$ $>0,05$. Các yếu tố mô bệnh học, độ dầy $u$, Clark, giai đoạn phát triển, vệ tinh, loét u, xâm nhập mạch, nhân chia, lympho xâm nhập u, số hạch khu vực di căn, giai đoạn bệnhsống thêm 5 năm toàn bộ là khác nhau, có ý nghĩa với $p<0,05$.

\section{BÀN LUẬN}

\section{1. Đặc điểm lâm sàng, mô bệnh học}

4.1.1. Tuổi, giới, vị trí u: Nghiên cứu của chúng tôituổi trung bình $55,0 \pm 0,9$; thấp nhất 18 , cao nhất 85 tuổi; gặp nhiều là 40 đến 79 tuổi $83,5 \%$. Tỷ lệ nữ/ nam là 1,13. Vị trí gặp nhiều ở chi dưới $62,3 \%$, thân mình $18,3 \%$, chi trên $10,7 \%$ và đầu cổ $8,7 \%$. Kết quả này tương tự với kết quả của Balch, tuổi trung bình 53,2; tỷ lệ nữ/ nam là 1,2 , vị trí hay gặp ở chi dưới $56 \%$, chi trên $11,9 \%$, thân mình $22,4 \%$, đâu cổ $9,7 \%$ [4].

4.1.2. Mô bệnh hoc, độ dây u, Clark u: Xết quảnghiên cứu nàythể lan tràn nông tỷ lệ cao $61,7 \%$, thể nốt $17 \%$, thể nốt ruồi son $11,3 \%$ và thể nốt ruồi son đỉnh $10 \%$. Bề dây $1,1-2,0 \mathrm{~mm}$ (T2) là 2,8\%, 2,1-4,0mm (T3) là 29,8\%, > $4,0 \mathrm{~mm}$ (T4) là 67,4\%. Clark II là 5,7\%, Clark III 8,5\%, Clark IV 34,5\%,Clark V 51,8\%.Nghiên cứu của Balch trên 17600 bệnh nhân thể lan tràn nông $70 \%$, thể nốt $15 \%$, thể nốt ruồi son $8 \%$ và thể nốt ruồi son đỉnh $5 \%$.U có bề dày dưới $1 \mathrm{~mm} 18.1 \%$ ， 1,01-2mm 29,9\%，2,01-4mm
$30,5 \%$ và trên $4 \mathrm{~mm} 21,5 \%$, mức độ Clark IV và Vchiếm 47,3\% [4]. Nghiên cứu của chúng tôi độ dầy u T3, T4 và Clark IV, $V$ chiếm tỷ lệ cao hơn, là do bệnh nhân của chúng tôi thường đến viện ở giai đoạn không sớm.

4.1.3. Giai đoạn phát triển, vệ tỉnh quanh u, loét u: Kết quả nghiên cứu nàygiai đoạn phát triển thẳng đứng $75,2 \%$, có nhân vệ tinh 30,5\%, không vệ tinh $69,5 \%$, có loét ù $43,2 \%$, không loét $56,7 \%$. Nghiên cứu của Garbe C, thấy $62,9 \%$ trường hợp có phát trát triển thẳng đứng, $18,3 \%$ có nhân vệ tinh và $25 \%$ có loét khối u [5] sự khác nhau này là do các bệnh nhân của họ thường phát hiện ở giai đoan sớm nên giai đoạn phát triển thẳng đứng, nhân vệ tinh, loét u có tỷ lệ thấp hơn nghiên cứu của chúng tôi.

4.1.4. Xâm nhập mạch, nhân chia, lympho xâm nhập u: Kết quả nghiên cứu này có xâm nhập mạch $22 \%$, u xâm lấn trung bì thì có số nhân chia > 6/mm2 là 38,3\%, nhân chia < $1 / \mathrm{mm} 2$ là $28,4 \%$. Lympho xâm nhập u dầy đặc $30,5 \%$, thưa thớt 33,3\%. Kết quả nghiên cứu của chúng tôi cao hơn nghiên cứu của Garbe $\mathrm{C}$ thấy xâm nhập mạch $16,2 \%$, u xâm lấn trung bì có nhân chia > 6/ mm2 là $23,4 \%$, số nhân chia $<1 / \mathrm{mm} 2$ là $16,5 \%$, lympho xâm nhập dầy đặc $22,6 \%$, thưa thớt $30,2 \%[5]$.

\subsubsection{Số hạch khu vực di căn, giai đoạn}


bệnh: Nghiên cứu của chúng tôi di căn hạch là $54,1 \%$, giai đoạn 2 là 45,9\%, giai đoạn 3 là $54,1 \%$. Tỷ lệ di căn hạch khu vực cao hớn nhiều so với nghiên cứu của Garbe $C$ di căn hạch khu vực $18,8 \%$, giai đoạn 2,3 tương ứng là $48,3 \%$ và $18,8 \%$ [5]. Nguyên nhân là bệnh nhân của chúng tôi thường đến viện ở giai đoạn muộn hơn.

\subsection{Một số yếu tố có thể ảnh hưởng tới kêt quả điều trị}

4.2.1. Nhóm tuổi, giới, vị trí u: nghiên cứu của chúng tôi nhóm $\leq 50$ và $>50$ tuổi, sống thêm 5 năm là khác nhau, tương ứng $49,3 \%$ so với $38,7 \%$ nhưng không có ý nghĩa, p > 0,05. Nam và nữ sống thêm 5 năm là khác nhau, tương ứng $44,6 \%$ so với $40,7 \%$, không có ý nghĩa, p > 0,05. Vị trí u, sống thêm 5 năm là khác nhau có ý nghĩa, $p<0,05$, cụ thểlà đầu cổ, thân mình, chi trên và chi dưới tương ứng là $69,1 \%, 54,5 \%$, $38,3 \%$ và $35,3 \%(p=0,004)$. Nghiên cứu của Balch sống thêm 5 năm ở nhóm $\leq 50$ tuổi cao hơn nhóm> 50 tuổi, nhóm bệnh nhân nữ cao hơn nhóm nam, không có ý nghĩa, $p>0,05$, vị trí u ở đầu cổ sống thêm 5 năm cao nhất và vị trí u ở chi dưới sống thêm 5 năm thấp nhất, tương ứng là $72,5 \%$ và $45,3 \%(p<0,05)[4]$.

4.2.2. Típ mô bệnh học, độ dây u: nghiên cứu của chúng tôi, sổng thểm 5 năm thể lan tràn nông là $70,4 \%$, thể nốt 4,2\%, thể nốt ruồi son $62,7 \%$ và thể nốt ruồi son đỉnh $13,3 \%$ ( $p<$ $0,0001)$. Sống thêm 5 năm độ dầy khối u T2, T3 là 89,5 và $T 4$ là $22,3(\mathrm{p}<0,0001)$. Kết quả này tương tự kết quả của Balch, trên 17600 bệnh nhân, sống thêm 5 năm thể lan tràn nông $78 \%$, thể nốt $15 \%$, thể nốt ruồi son $68,2 \%$ và thể nốt ruồi son đỉnh $21,5 \%$, sống 10 năm của bệnh nhân có $\mathrm{T} 1, \mathrm{~T} 2, \mathrm{~T} 3$, T4 lần lượt là 92\%, 80\%, $63 \%, 50 \%$ [4].

4.2.3. Clark, giai đoạn phát triển: Nghiên cứu của chúng tôi, sống thêm 5 năm Clark $2,3,4$ là $19,7 \%$ và Clark 5 là $79,7 \%(p<0,0001)$. Nghiên cứu của Clark sống thêm 8 năm là $96,3 \%$ ở bệnh nhân Clark II, 76,1\% ở Clark III, 60,7\% ở Clark IV, 38,5\% ở Clark V [6]. Nghiên cứu của chúng tôi, sống thêm 5 năm nhómcó giai đoạn phát triên thẳng đứng là $20,5 \%$, nhóm có giai đoạn tỏa tia là $92,6 \%(p<0,0001)$. Nghiên cứu của Barnhill trên 540 bệnh nhân, thấy sống trên 5 năm của nhóm có giai đoạn phát triển thẳng đứng $34 \%$, trong khi nhóm có giai đoạn tỏa tia $98,2 \%(p<0,05)[7]$.

4.2.4. Nhân vệ tinh,loét u: Nghiên cứu của chúng tôi, sống thêm 5 năm nhóm có nhân vệ tinh $5 \%$, nhóm không có nhân vệ tinh $77,1 \%$.Sống thêm nhóm có loét $13, \%$ và nhóm không loét $78,1 \%(p<0,0001)$. Nghiên cứu của Barnhill trên 540 bệnh nhân, thấy rằng sống trên 5 năm của bệnh nhân không có vệ tinh vi thể và có vệ tinh vi thể lần lượt là 90 và $66,7 \%$ [7]. Nghiển cứu của Balch, trên 17600 bệnh nhân, thấy sự có mặt của loét làm giảm tỷ lệ sống của bệnh nhân ở tất cả các nhóm bề dày u, UT1 có loét giảm tỷ lệ sống sót $5 \%$ so với u không có loét, đối với u T4 tỷ lệ giảm này lên tới 22\% [4].

4.2.5. Xâm nhập mạch, tỷ lệ nhân chia: Nghiên cứu của chúng tôi, sống thêm 5 năm nhóm có xâm nhập mạch là 3,2\%, nhóm không xâm nhập mạch $63,8 \%(p<0,0001)$. Sống thêm 5 năm nhóm nhân chia < $1 \mathrm{~mm} 2$ là $80,7 \%$, nhóm nhân chia $1-6 \mathrm{~mm} 2$ là $58,5 \%$ và nhóm nhân chia $>6 \mathrm{~mm} 2$ là $12,9 \%(p=0,0015)$. Nghiên cứu của Barnhill, trên 540 bệnh nhân thây sống trên 5 năm của bệnh nhân có xâm nhập mạch là $12,8 \%$ và không có xâm nhập mạch là $42,1 \%$. Sống thêm 5 năm là $98,7 \%$ với bệnh nhân có nhân chia $<1 / \mathrm{mm} 2,85,1 \%$ có nhân chia từ 1$6 / \mathrm{mm} 2,68,2 \%$ có nhân chia trên $6 / \mathrm{mm} 2$ [7].

4.2.6. Lympho xâm nhập u, số hạch khu vực di căn, giai đoạn bệnh: Trong nghiên cứu này sống thêm 5 năm của bệnh nhân ở giai đoạn phát triển thẳng đứng nhóm lympho xâm nhập dây đặc là $80,5 \%$, nhóm thưa thớt là $47,5 \%$ và nhóm không có lympho bào xâm nhập là $20,6 \%$ $(p=0,0028)$. Sống thêm 5 năm nhómcó 1 hạch khu vực di căn là $21,7 \%$, nhóm 2 đến 3 hạch di căn là $16,4 \%$, nhóm > 3 hạch di căn là $8,7 \%(p$ $=0,0032)$. Sống thêm 5 năm giai đoạn 2,3 là $77,7 \%$ và $17,3 \%$. Nghiên cứu củaGarbe $C$ thây sống 5 và 10 năm của bệnh nhân ở giai đoạn phát triển thẳng đứng có lympho xâm nhập u dày đặc lần lượt là $77 \%$ và $55 \%$, trong khi đó lympho xâm nhập thưa thớt là $53 \%$ và $45 \%$ và ở nhóm vắng mặt sự xâm nhập của lympho là $37 \%$ và $27 \%$. Sống thêm 5 năm khi 1 hạch khu vực di căn là $50 \%$, có 2-3 hạch di căn thì sống 5 năm $37 \%$, di căn 4 hạch trở lên thì sống trên 5 năm chỉ còn $27 \%$. Sống thêm 5 năm giai đoại 2,3 là $79,5 \%$ và $26,4 \%[5]$.

\section{KẾT LUẦN}

\section{Đặc điểm lâm sàng và mô bệnh học}

- Bệnh thường gặp ở lứa tuổi 40 đến 79 , tuổi trung bình là $55,0 \pm 0,9$, tuổi thấp nhất là 18 và tuổi cao nhất là 85 , tỳ lệ nữ/nam là 1,13 , vị trí hay gặp là chi dưới $62,3 \%$.

- Thể lan tràn nông chiếm tỷ lệ cao $61,7 \%$.Bề dây $2,1-4,0 \mathrm{~mm}$ là $29,8 \%$, > 4,0mm là $67,4 \%$. Clark V tỷ lệ cao $51,8 \%$, Clark IV là $34 \%$. Giai đoạn thẳng đứng $75,2 \%$, nhân vệ tinh $30,5 \%$, loét u 43,2\%, xâm nhập mạch 22\%. 
- U xâm lấn trung bì có số nhân chia > $6 / \mathrm{mm} 2$ cao nhất 38,3\%, thấp nhất nhân chia < $1 / \mathrm{mm} 2$ là $28,4 \%$, lympho xâm nhập u dầy đă̆c $30,5 \%$, không có lympho bào xâm nhập 36,2\%. Chưa di căn hạch là 45,9\%, giai doạn 2 là $45,9 \%$, giai đoạn 3 là $54,1 \%$.

\section{Một số yếu tố tiên lượng}

- Tỷ lệ sống thêm 5 năm toàn bộ $42,4 \%$.

- Vị trí khối u, típ mô bệnh học, độ dầy u, mức độ Clark, giai đoạn phát triển, nhân vệ tinh, loét u nguyên phát, xâm nhập mạch, tỷ lệ nhân chia, lympho xâm nhập u, số hạch khu vực di căn, giai đoạn bệnh là những yếu tố tiên lượng quan trọng ảnh hưởng đến tỷ lệ sống thêm.

\section{TÀI LIÊU THAM KHẢO}

1. Albino A.P, Reed J.A., McNutt N.S et al. (1997). Molecular Biology of Cutaneous Melanoma, Principles and practice of Oncology. Lippincott Raven, 2, 46.
2. Marc Hurlbert (2020). 2020 Melanoma mortality rates decreasing despite ongoing increase in incidence. Melanoma research Alliance.

3. Phạm Hoàng Anh và cộng sự (1993), Ung thư Hà Nội 1991- 1992, y học Việt Nam; chuyên đề ung thư, tập 173, số 7, 14-21.

4. Balch CM, Joong SJ, et al. (2001). Prognostic factors analysis of 17.600 melanoma patients: validation of the American Joint Committee on Cancer melanoma staging system. J Clin Oncol,19(16), 3622-34.

5. Garbe C., Butner P., Bertz J. et al. (1995) Primary cutaneous melanoma, identification of prognostic group and estimation of individual prognostic for 6599 patients. Cancer, 75, 2484-91.

6. Clark WH Jr Elder DE, et al. (1989). Model predicting survival in stage I melanoma based on tumor progression. JNCI, 81, $1893-1904$.

7. Barnhill RL, Fine JA, Roush GC, Berwick M. (1996). Predicting five-year outcome for patients with cutaneous melanoma in a population-based study. Cancer, 78,427-432.

\section{SỰ HÀI LÒNG VỚI CÔNG VIỆC CỦA Đİ̂̀U DƯỡNG VÀ MộT SỐ YẾU TỐ ẢNH HƯỞNG TẠI BỆNH VIỆN ĐA KHOA TRUNG TÂM TIỀN GIANG NĂM 2019}

\section{TÓM TẮT}

Nghiên cứu "Sứ hài lòng với công viêc của điều dưỡng và một số yễu tố ảnh hưởng tại Bệnh viện Đa khoa Trung tâm Tiên Giang năm 2019" được thực hiện từ tháng 3/2019 đến tháng $9 / 2019$, bằng phương pháp nghiên cứu mô tả cắt ngang kết hợp phân tích định lượng và định tính, phát vẩn 257 điều dưỡng đang làm việc tại các khoa phòng của Bệnh viện Đa khoa Trung tâm Tiền Giang, đồng thời tiến hành phỏng vấn sâu một số lãnh đạo Bệnh viện và các khoa phòngvới 2 mục tiêu: (1) Mố tả sự hài lòng với công việc của điều dưỡng tại Bệnh viện Đa khoa Trung tâm Tiền Giang năm 2019; (2) Phân tích một số yếu tố ảnh hưởng đển sự hài lòng với công việc của điêu dưỡng tại Bệnh viện Đa khoa Trung tâm Tiên Giang năm 2019. Kết quả nghiên cứu cho thấy: điểm trung bình hài lòng về môi trường làm việc là $3,35 / 5$ (thang điểm 5) chiếm tỉ lệ 67\%; điểm trung bình hài lòng chung với lãnh đao trực tiếp, đồng nghiệp là 3,71 (thang điểm 5), chiếm tî lệ 74,2\%; điểm trung bìnhhài lòng chung với quy chế nội bộ, tiền lương, phúc lợi là 3,48 (thang điểm 5), chiếm tî lệ 69,6\%. Điểm trung bìnhhài lòng chung với công việc, cơ hội học tập và thăng tiến

\footnotetext{
${ }^{1}$ Bệnh viện $Đ K T T$ Tiền Giang

2 Trường $Đ H Y$ Dước, $Đ H$ Quốc gia $H N$

Chịu trách nhiệm chính: Lê Thị Hằng

Email: hang.vnu65@gmail.com

Ngày nhận bài: 14/8/2021

Ngày phản biên khoa hoc: 11/9/2021

Ngày duyệt bài: 29/9/2021
}

\section{Nguyễn Ngọc Bảo Châu ${ }^{1}$, Lê Thị Hằng ${ }^{2}$ và $\mathrm{CS}$}

là 3,55 (thang điểm 5), chiếm tỉ lệ $71 \%$. Một số yếu tố ảnh hưởng tiêu cực đến sư hài lòng với công việc của điều dưỡng như: cơ sở vật chất cũ xuống cấp, trang bị bảo hộ lao động như khẩu trang còn thiếu, lương còn thấp, áp lực công việc lớn nhưng chưa được quan tâm của lãnh đạao khoa phòng, một số bệnh nhân thiếu tôn trọng và hợp tác với điều dưỡng... Nghiên cứu chỉ ra, lãnh đạo cần quan tâm và đối xử bình đẳng với điều dưỡng, tạo nguồn kinh phí chi trả tiền lương và phụ cấp tương xứng với cống hiến của điều dưỡng do bệnh viện tự chi hoàn toàn và phân công công việc phù hợp với vị trí của từng điêuu dưỡng. Đối với đội ngũ điều dưỡng cần rèn luyện, trau dồi, học tập nâng cao trình độ chuyên môn, nghiệp vụ, cập nhật kiến thức mới và thực hành tốt y đức.

Tư khóa: Sự hài lòng, điều dương.

\section{SUMMARY}

SATISFACTION WITH THE JOB OF NURSING AND SOME INFLUENCING FACTORS AT TIEN GIANG CENTRAL GENERAL HOSPITAL IN 2019

Research "Satisfaction with the job of nursing and some influencing factors at Tien Giang Central General Hospital in 2019" was conducted from March 2019 to September 2019 with the goal: 1) Describe the satisfaction with the job of nursing in Central Hospital in Tien Giang in 2019. 2)Analyze some factors affecting the job satisfaction of nursing at Central General Hospital Tien Giang Center in 2019. The research method is cross-sectional description combining quantitative and qualitative analysis. The 